\title{
Mepolizumab for the treatment of severe eosinophilic asthma
}

\section{Mepolizumab para el tratamiento de asma grave eosinofilica}

\section{Armando Partida-Gaytán, 1,2 Luis Torre-Bouscoulet, ${ }^{3}$ Marco Polo Macías, ${ }^{2}$ Alejandro Raimondi, ${ }^{4}$ Emilio Pizzichini ${ }^{5,6}$}

\author{
1Fundación Mexicana para Niñas y Niños con Inmunodeficiencias Primarias A. C., Ciudad de México, \\ México \\ ${ }^{2}$ GlaxoSmithKline, Ciudad de México, México \\ 3Instituto de Desarrollo e Innovación en Fisiología Respiratoria, Ciudad de México, México \\ ${ }^{4}$ GlaxoSmithKline, Buenos Aires, Argentina \\ 5 Universidad Federal de Santa Catarina, Florianópolis, Brasil \\ ${ }^{6} G$ laxoSmithKline, Brentford, Middlesex, Reino Unido
}

\section{ORCID}

Armando Partida-Gaytán, 0000-0002-5337-0502; Luis Torre-Bouscoulet, 0000-0003-2183-7662; Marco Polo Macías, 0000-0002-5337-0502; Alejandro Raimondi, 0000-0003-2384-5543;

Emilio Pizzichini, 0000-0001-7046-9996

Correspondencia: Armando Partida-Gaytán. armando.x.partida@gsk.com

Recibido: 2020-07-08

Aceptado: 2020-10-18

DOl: 10.29262/ram.v67i7.780

Este artículo debe citarse como: Partida-Gaytán A, Torre-Bouscoulet L, Macías MP, Raimondi A, Pizzichini E. Mepolizumab para el tratamiento de asma grave eosinofílica.Rev Alerg Mex. 2020;67 Supl 3:s83-s101.

\section{Abstract}

Severe asthma is a heterogeneous and complex disease that affects approximately $5 \%$ of patients with asthma and is associated with a significant burden of symptoms, frequent severe exacerbations, and negative impacts on functionality and quality of life. Different innovation strategies have updated the therapeutic options available for these patients, but monoclonal antibodies represent the alternative with the greatest clinical relevance. It is important that the asthma specialist is kept up-to-date to correctly identify those patients who may benefit from treatment with these medications. This article provides an up-to-date and practical review focused on mepolizumab, a humanized anti-IL-5 monoclonal

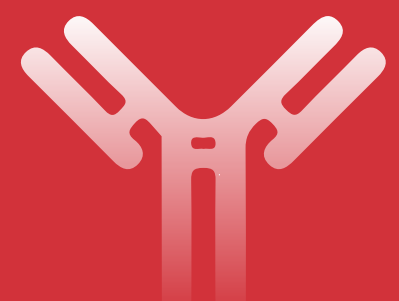


antibody approved as an add-on treatment in patients with severe eosinophilic asthma. In this document, a synthesis of the evidence of efficacy, safety and effectiveness of mepolizumab has been made with the aim of providing a consultation and decision support tool for the specialist who evaluates, diagnoses and treats patients with severe asthma. In controlled conditions of clinical trials and in real-life studies, mepolizumab has been documented to consistently and significantly reduce asthma exacerbations, improve disease control, and patients' quality of life; likewise, it decreases the dose or makes possible the withdrawal of systemic corticosteroids.

Key words: Severe asthma; Monoclonal antibody; Mepolizumab; Biological agent

\title{
Resumen
}

El asma grave es una enfermedad heterogénea y compleja que afecta aproximadamente al $5 \%$ de los pacientes con asma y se asocia a una importante carga de síntomas, exacerbaciones graves frecuentes e impactos negativos en la funcionalidad y calidad de vida. Diferentes estrategias de innovación han actualizado las opciones terapéuticas disponibles para estos pacientes, pero los anticuerpos monoclonales representan la alternativa con mayor relevancia clínica. Es importante que el especialista en asma se mantenga actualizado para identificar correctamente a los pacientes que pueden beneficiarse del tratamiento con estos medicamentos. Este artículo ofrece una revisión actualizada y práctica enfocada en mepolizumab, un anticuerpo monoclonal humanizado anti-IL-5 aprobado como tratamiento complementario en pacientes con asma grave eosinofílica. En este documento se ha realizado una síntesis de las evidencias de eficacia, seguridad y efectividad de mepolizumab con el objetivo de proveer una herramienta de consulta y apoyo en la toma de decisiones para el especialista que evalúa, diagnostica y trata pacientes con asma grave. En condiciones controladas de ensayos clínicos y en estudios de vida real se ha documentado que mepolizumab reduce consistente y significativamente las exacerbaciones del asma, mejora el control de la enfermedad y la calidad de vida de los pacientes; de igual forma, disminuye la dosis o hace posible el retiro de corticosteroides sistémicos.

Palabras clave: Asma grave; Anticuerpo monoclonal; Mepolizumab; Agente biológico

\author{
Abreviaturas y siglas \\ CEl, corticosteroide inhalado \\ CEOS, corticosteroide oral sistémico \\ IL, interleucina \\ LABA, broncodilatador de acción prolongada
}

\section{Introducción}

El asma grave es una enfermedad heterogénea y compleja que siempre representa un reto clínico para el especialista que atiende a estos pacientes. El tratamiento del asma grave se ha visto significativamente modificado en los últimos años. Los anticuerpos monoclonales que inhiben vías específicas de señalización involucradas en la fisiopatología del asma han demostrado su utilidad alrededor del mundo en el tratamiento de miles de individuos con asma grave. Los especialistas en asma saben que los pacientes con la forma grave de la enfermedad constituyen una minoría en el universo de pacientes con asma; sin embargo, reconocen que son ellos quienes tienen la mayor carga sintomática, la mayor limitación en funcionalidad, el peor impacto en calidad de vida y el mayor riesgo de exacerbaciones graves e, incluso, de mortalidad. El especialista en asma requiere 
mantenerse actualizado para identificar correctamente a los pacientes que pueden beneficiarse del tratamiento con anticuerpos monoclonales. Este artículo ofrece una revisión actualizada y práctica, enfocada en mepolizumab, en la que los autores realizan una síntesis de las evidencias de eficacia y seguridad de los ensayos clínicos pivote; así como las observaciones a largo plazo de estudios de extensión y de vida real con el objetivo de proveer una herramienta de consulta y apoyo en la toma de decisiones para el especialista que evalúa, diagnostica y trata pacientes con asma grave.

\section{Definición y prevalencia de asma grave}

En la literatura y en la práctica clínica rutinaria, el término asma grave ha sido utilizado como sinónimo de asma difícil de tratar, asma de difícil control, asma grave, asma severa, asma refractaria, asma corticorresistente, asma corticodependiente, asma grave persistente, etcétera; lo que ha resultado en heterogeneidad y falta de claridad cuando el clínico quiere referirse a sus pacientes o busca evidencia clínica aplicable a ellos. La colaboración de múltiples expertos de la Sociedad Respiratoria Europea y de la Sociedad Americana de Tórax resultó en una clasificación de asma grave que cumple con suficiencia los estándares de investigación, así como los de la práctica clínica. Esta clasificación ha permitido homogeneizar un concepto operacional del paciente con asma grave, lo que favorece la claridad en la información que se genera. ${ }^{1}$

El paciente con asma grave se define como aquel que requiere tratamiento con altas dosis de corticosteroide inhalado ( $\mathrm{CEI} \geq 1000 \mu \mathrm{g}$ de propionato de fluticasona o el equivalente de otros $\mathrm{CEI}^{2}$ ), asociado a un segundo controlador (por ejemplo, broncodilatador de acción prolongada [LABA], antileucotrienos o teofilina), con o sin corticosteroide oral sistémico (CEOS) continuo para lograr el control clínico del asma; o en quien, a pesar de este tratamiento, no se logra el control. La falta de control se define como cualquiera de las siguientes condiciones:

- Presencia de dos o más exacerbaciones que requieren tratamiento con ciclos cortos de CEOS (tres o más días)

- Presencia de una o más exacerbaciones que requieren hospitalización, ingreso a terapia intensiva o ventilación mecánica.

- Persistencia de síntomas (identificables con cualquiera de los instrumentos validados disponibles: Asthma Control Test, Asthma Control Questionnaire, National Asthma Education and Prevention Program, Global Initiative for Asthma).

- Persistencia de un volumen espiratorio forzado en el primer segundo $<80 \%$ del esperado.

- Deterioro clínico al disminuir $25 \%$ o menos la dosis de CEI o CEOS.

Para el paciente, el asma grave implica persistir con síntomas, requerir más medicamentos, tener exacerbaciones frecuentes con impacto negativo en la funcionalidad y calidad de vida, así como estar expuesto a efectos adversos por el uso prolongado de medicamentos en altas dosis. ${ }^{3}$ Para los sistemas de salud, el asma grave representa $>50 \%$ de los gastos erogados por dicho diagnóstico, principalmente relacionado con costos directos por exacerbaciones, visitas a urgencias y hospitalizaciones. ${ }^{4,5}$

En México se ha considerado una prevalencia de asma de 8 a $12 \%$ en escolares y adolescentes y de 5 a $7 \%$ en adultos. ${ }^{6,7,8}$ Estas cifras permiten calcular que entre 6 y 14 millones de mexicanos requieren atención por diagnóstico de asma. ${ }^{9}$ En términos generales se estima que entre 5 y $10 \%$ de los pacientes con asma padece el espectro grave de la enfermedad; sin embargo, la gravedad en la mayoría (de 50 a $75 \%$ de los casos) suele 
explicarse por la falta de adherencia al tratamiento, mala técnica al usar los dispositivos de inhalación, falta de control ambiental o la combinación de estos factores. ${ }^{1,10}$ Aproximadamente entre 3.7 y $5 \%$ de los pacientes con asma tienen asma grave a pesar de buena adherencia al tratamiento y adecuada técnica en el uso de dispositivos de inhalación. ${ }^{11}$ Estas cifras han sido obtenidas de estudios con bases poblacionales y muestreos probabilísticos, lo que permite estimar, con razonable respaldo, que entre 300000 y 700000 mexicanos padecen asma grave que requiere evaluación y tratamiento especializado. $6,7,8,9,11$

\section{Opciones terapéuticas en pacientes con asma grave}

Existen varios documentos identificados como guías de tratamiento que han recolectado, discutido y presentado las opciones terapéuticas de los pacientes con asma grave (por ejemplo, Global Initiative for Asthma, British Guideline on the Management of Asthma, Guía Española del Manejo del Asma, National Asthma Education and Prevention Program, Guía Mexicana del Asma). ${ }^{12,13,14,15,16}$ Las intervenciones farmacológicas en los pacientes con asma grave incluyen un tratamiento estándar basado en CEI a dosis altas junto con uno o más de otros medicamentos de control, tales como LABA, antileucotrienos, teofilina, antimuscarínicos, macrólidos e, incluso, CEOS de mantenimiento. ${ }^{12,13,14,15,16}$

El creciente entendimiento de las vías de señalización entre el epitelio respiratorio bronquial y el sistema inmune involucradas en la fisiopatología del asma, junto con los avances biotecnológicos de la medicina moderna, han impulsado significativamente diversas opciones terapéuticas en asma grave. En las últimas dos décadas se han desarrollado diferentes medicamentos biotecnológicos, entre ellos los anticuerpos monoclonales. Los anticuerpos monoclonales representan opciones terapéuticas agregadas al tratamiento estándar, que han demostrado ser eficaces y seguras para el tratamiento de miles de pacientes con asma grave en todo el mundo. ${ }^{17}$

\section{Qué es mepolizumab y su mecanismo de acción}

Mepolizumab es un anticuerpo monoclonal recombinante humanizado que se une con alta afinidad y especificidad a la interleucina (IL) 5. Las características moleculares de mepolizumab se muestran en la figura 1.

IL-5 es la citocina más importante para la regulación de los eosinófilos en sangre periférica y a nivel tisular. La señalización de IL-5 mediante su receptor es responsable de la expansión celular, egreso desde la médula ósea hacia la sangre periférica, maduración, activación y sobrevida de los eosinófilos. Mepolizumab se une con alta afinidad y especificidad a IL-5, bloqueando su interacción con el receptor de esta interleucina, lo que inhibe su cascada de señalización. ${ }^{198}$ Aunque el mecanismo de acción de mepolizumab no ha sido completamente descrito, bloquear el efecto biológico de IL-5 resulta en disminución de la inflamación eosinofílica, como se puede apreciar en la figura 2 y en el video accesible tras escaneo del código QR.

\section{Indicaciones aprobadas en México}

Mepolizumab está aprobado en México como tratamiento complementario al tratamiento estándar en pacientes con asma grave eosinofílica a partir de los 12 años de edad. ${ }^{19} \mathrm{La}$ información acumulada de las diferentes cohortes de pacientes con asma grave señala que hasta el $79 \%$ de los pacientes con asma grave corresponden al fenotipo eosinofílico. ${ }^{20,21}$ 
Regiones Vh

humanizadas

Regiones constantes

$\mathrm{CH}$ humanas

Regiones determinantes de complementariedad

Puentes disulfuro
intercatenarios
Regiones Vi

humanizadas

Regiones constantes

Ck humanas

Carbohidratos

\section{Región $\mathrm{Vh}=$ variable de cadena pesada}

Región $\mathrm{Vi}=$ variable de cadena ligera

Región $\mathrm{CH}=$ constante de cadena pesada

Región Ck = constante de cadena ligera kappa

Peso molecular $=149 \mathrm{kDa}$-unión de alta afinidad a IL-5 [constante de disociación de 100 pM].

Mepolizumab es producido en células de ovarios de hámster chino $[\mathrm{CHO}$ ) mediante un proceso estándar de producción de anticuerpos de 12 pasos

Glucosilación en asparagina 229 con oligosacáridos tipo complejos biantena [N-glicosilación]

Figura 1. Características moleculares de mepolizumab. La imagen ilustra las principales características moleculares de mepolizumab, un anticuerpo monoclonal humanizado anti-interleucina 5. European Medicines Agency. Assessment Report Nucala I International non-proprietary name: mepolizumab, 2015. Disponible en: https://www.ema.europa.eu/en/documents/assessment-report/nucala-epar-public-assessment-report_en.pdf

\section{Criterios de elegibilidad para tratamiento con mepolizumab}

La identificación del perfil del paciente con asma grave en el que puede predecirse una respuesta clínica favorable al inhibir la vía de IL-5 con mepolizumab se basa en dos criterios:

- Paciente tratado con dosis altas de CEI más un segundo controlador (LABA, antileucotrieno, teofilina), con o sin CEOS continuo de mantenimiento, y que en los últimos 12 meses hubiera presentado dos o más exacerbaciones clínicamente relevantes por las que hubiera requerido ciclo corto de esteroide, visita a urgencias o a hospitalización.

- Identificación del biomarcador que predice una respuesta clínica significativa favorable: cuenta de eosinófilos en biometría hemática $\geq 150$ células $/ \mu \mathrm{L}$ al momento de la evaluación del paciente o que en el historial de los últimos 12 meses registrara $\geq 300$ células $/ \mu \mathrm{L}$. 


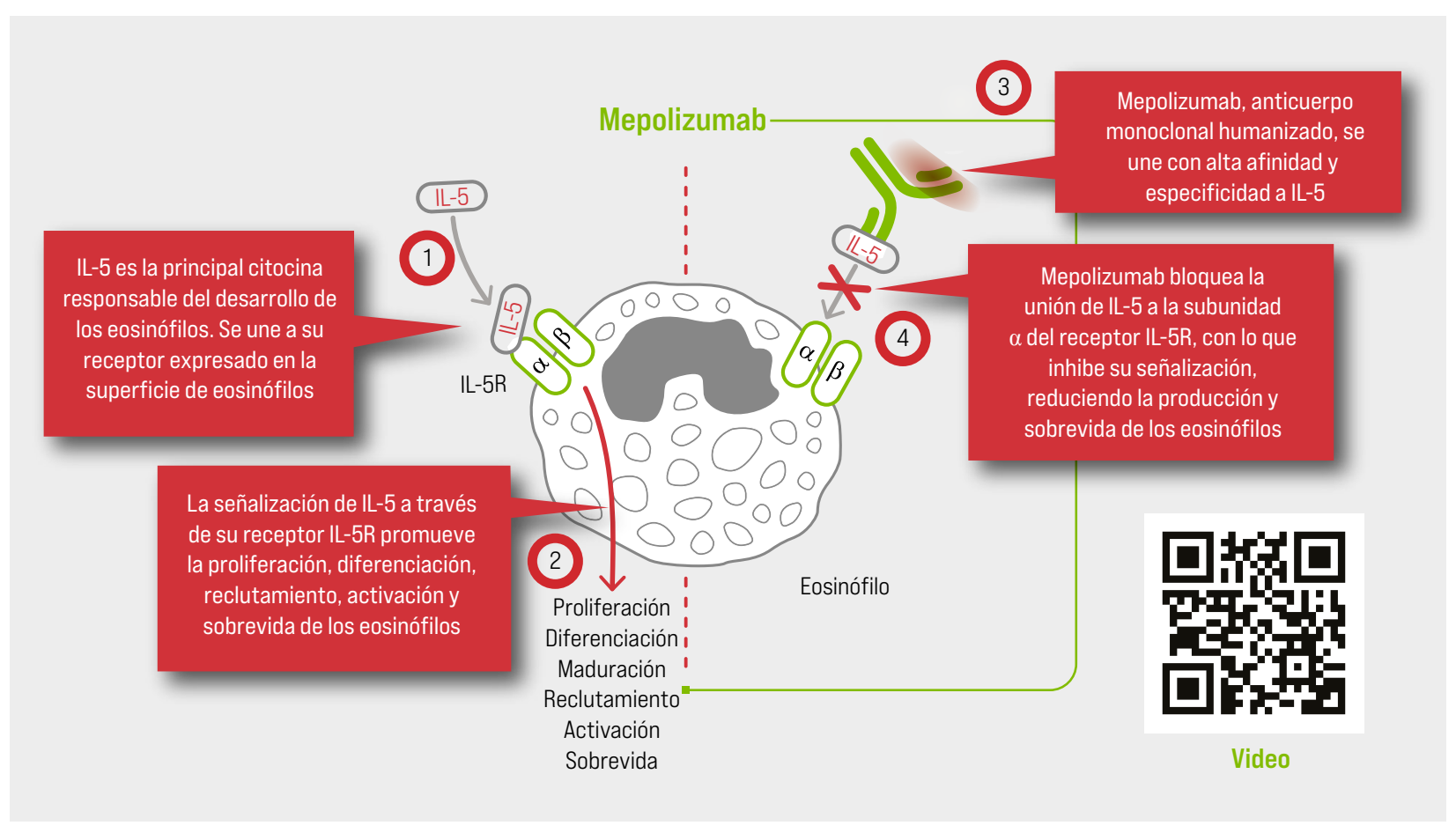

Figura 2. Mecanismo de acción de mepolizumab, anticuerpo monoclonal anti-interleucina 5 [IL-5]. La imagen ilustra en los puntos 1 y 2 la señalización y el efecto biológico de IL-5 sobre los eosinófilos. Los puntos 3 y 4 muestran cómo mepolizumab inhibe el efecto biológico de IL-5 al unirse y bloquear su interacción con su receptor. Al escanear el código QR con su teléfono inteligente lo llevará a un video ilustrativo del mecanismo de acción de mepolizumab.

\section{Eficacia clínica, tolerabilidad y seguridad}

Las evidencias clínicas de eficacia y seguridad de mepolizumab han sido publicadas en cuatro estudios principales conocidos por sus pseudoacrónimos como DREAM, MENSA, SIRIUS y MUSCA. ${ }^{22,23,24,25}$ En estos estudios, mepolizumab agregado a tratamiento estándar demostró reducir de 50 a $69 \%$ las exacerbaciones clínicamente relevantes, disminuir aproximadamente en $50 \%$ la dosis de CEOS en pacientes corticodependientes, mejorar significativamente la calidad de vida y el control del asma. Un resumen de las características más importantes de estos estudios y sus resultados se describen en el cuadro 1.

Publicaciones posteriores basadas en análisis post hoc de los ensayos clínicos han informado los siguientes hallazgos relevantes:

- A mayor número de eosinófilos en sangre periférica, mayor la reducción en las exacerbaciones $^{26}$ (figura 3).

- La eficacia de mepolizumab no se modifica si el paciente tiene asma eosinofílica alérgica o asma eosinofílica no alérgica ${ }^{27}$ (figura 4).

Tres estudios clínicos de extensión, conocidos como COLUMBA, COSMOS y COSMEX, han documentado la consistencia y durabilidad de la eficacia (reducción de exacerbaciones, disminución en dosis de CEOS, mejoría en control de la enfermedad y calidad de vida), así como el perfil de tolerabilidad y seguridad de mepolizumab hasta por 4.8 años. ${ }^{28,29,30}$ De particular interés es el estudio COSMEX, que evaluó el beneficio 


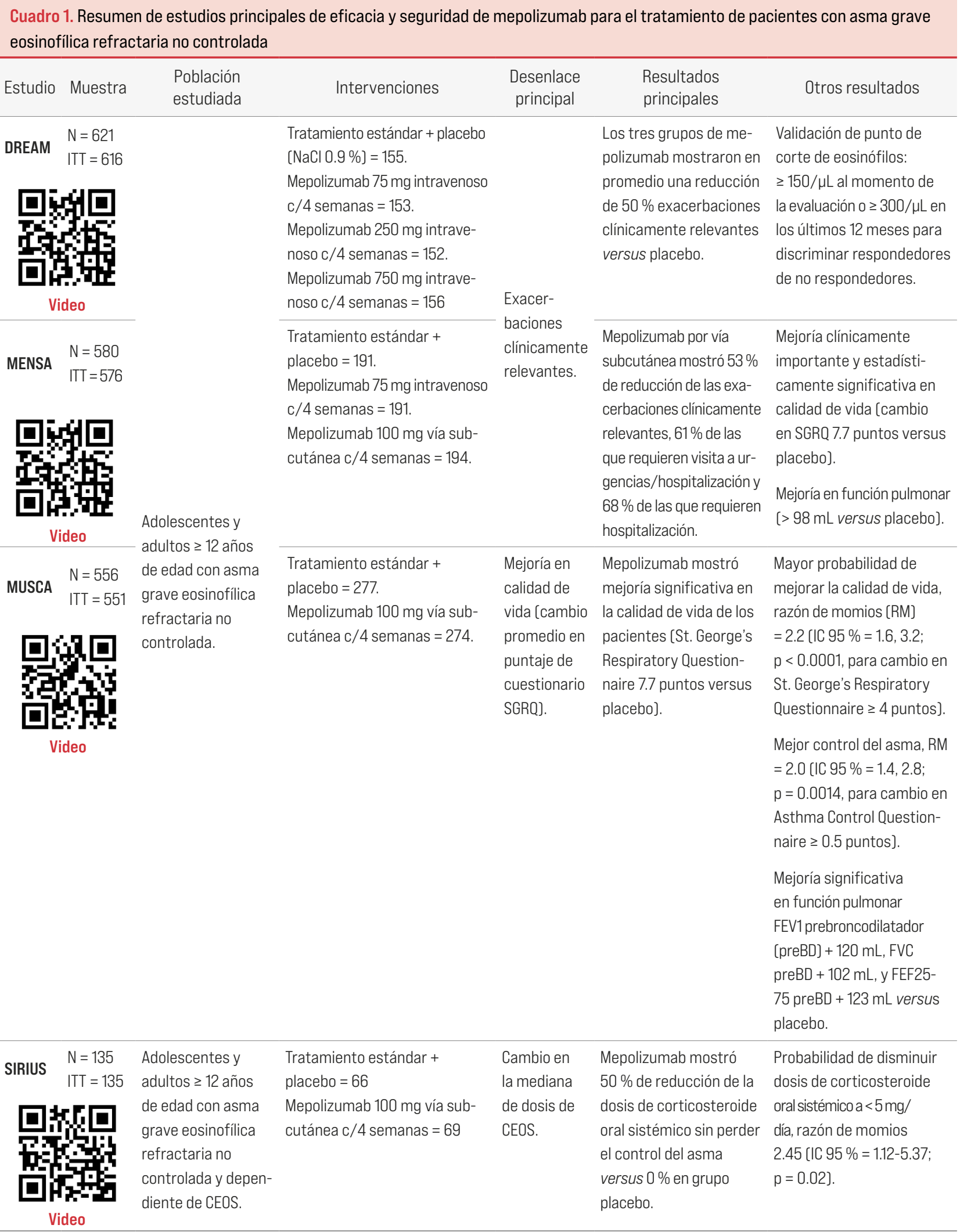


clínico de mepolizumab en pacientes con el espectro más grave de asma eosinofílica, es decir, antecedente de exacerbación de asma casi fatal o que requirió ventilación mecánica o ingreso a terapia intensiva). ${ }^{30}$ COSMEX fue un estudio de extensión de COSMOS, que a su vez fue un estudio de extensión de MENSA y SIRIUS. ${ }^{23,24,29,30}$ En COSMEX se acumuló información de 718 años-paciente de exposición a mepolizumab en pacientes con el espectro más grave del asma grave eosinofílica. En la figura 5 se muestran los principales resultados observados en esa población.

OSMO es otro estudio interesante por su acercamiento pragmático; en él se reclutaron pacientes con asma grave eosinofílica alérgica que continuaban teniendo dos o más exacerbaciones a pesar de tratamiento estándar y omalizumab. En OSMO, los pacientes continuaron el tratamiento estándar y se cambiaron a mepolizumab en lugar de omalizumab, con lo que y se documentaron mejorías estadísticamente significativas y clínicamente importantes en el control del asma, la calidad de vida y la reducción de las exacerbaciones (figura 6).

Mepolizumab ha demostrado un adecuado perfil de tolerabilidad y seguridad. Los eventos adversos reportados con mayor frecuencia (observados en $\geq 3 \%$ de los sujetos) durante las primeras 24 semanas de MENSA y SIRIUS en comparación con placebo fueron cefalea 19 versus $18 \%$, reacción en el sitio de inyección 8 versus $3 \%$, lumbalgia

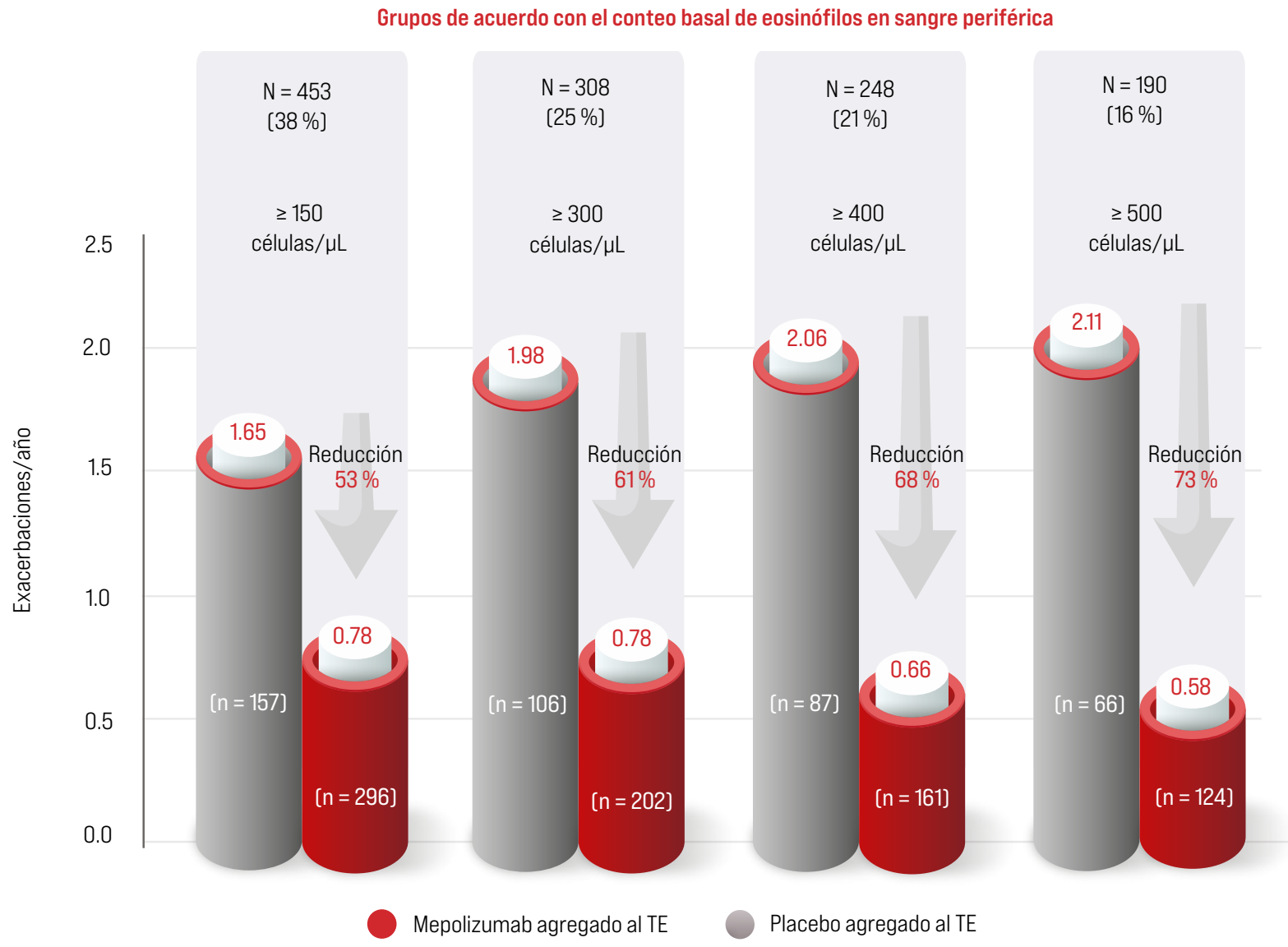

Figura 3. Gradiente de eficacia dependiente del conteo de eosinófilos en sangre periférica. En el gráfico se observa la eficacia [reducción de exacerbaciones] de mepolizumab en función del número de eosinófilos en la evaluación inicial. En las barras grises se observan las tasas anuales de exacerbaciones en los pacientes tratados con placebo, y en barras rojas, las de los pacientes tratados con mepolizumab. Todos los pacientes recibieron tratamiento estándar [TE]. 


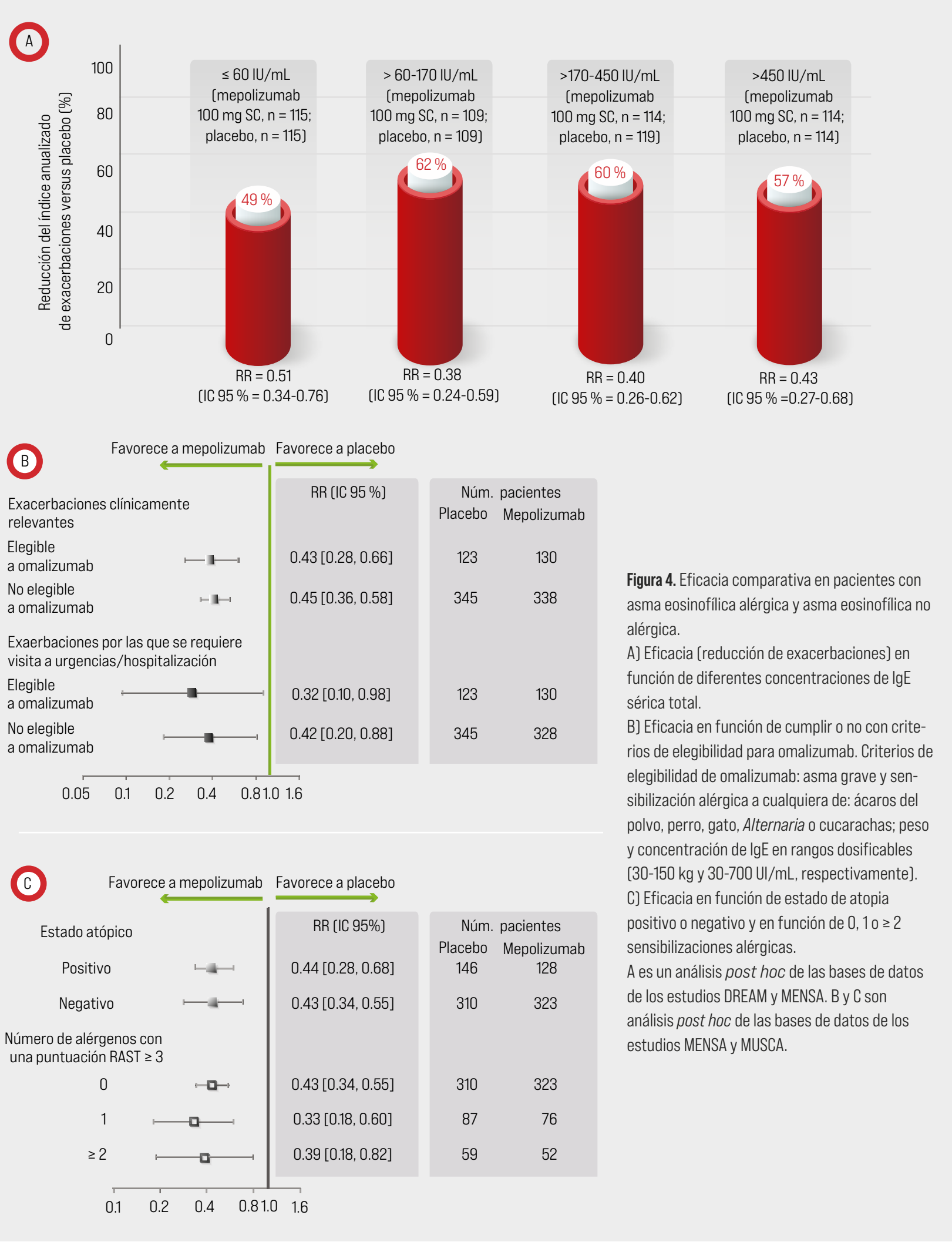




\begin{tabular}{|c|c|c|}
\hline \multicolumn{3}{|c|}{ Cuadro 2. Resumen de eventos adversos reportados en MENSA, SIRIUS y COLUMBA $23,24,28$} \\
\hline \multicolumn{3}{|c|}{$\begin{array}{l}\text { Eventos adversos ocurriendo en } \geq 3 \% \text { [y más común que en placebo] en las primeras } 24 \text { semanas } \\
\text { de los estudios MENSA y SIRIUS }\end{array}$} \\
\hline Evento adverso & $\begin{array}{c}\text { Mepolizumab } \\
\text { [n=263] } \\
\%\end{array}$ & $\begin{array}{c}\text { Placebo } \\
{[n=257]} \\
\%\end{array}$ \\
\hline Cefalea & 19 & 18 \\
\hline Reacción en sitio de aplicación. & 8 & 3 \\
\hline Lumbalgia & 5 & 4 \\
\hline Fatiga & 5 & 4 \\
\hline Influenza & 3 & 2 \\
\hline Infección del tracto urinario & 3 & 2 \\
\hline Dolor abdominal alto & 3 & 2 \\
\hline Prurito & 3 & 2 \\
\hline Eccema & 3 & $<1$ \\
\hline Espasmos musculares & 3 & $<1$ \\
\hline \multicolumn{3}{|c|}{$\begin{array}{l}\text { Perfil de seguridad en estudio de extensión COLUMBA [hasta } 4.8 \text { años de observación]. } \\
\text { Eventos adversos ocurriendo en } 10 \% .\end{array}$} \\
\hline Evento adverso & \multicolumn{2}{|c|}{$\begin{array}{l}\text { Pacientes }[n=347] \\
\%\end{array}$} \\
\hline Infección viral del tracto respiratorio superior & \multicolumn{2}{|c|}{49} \\
\hline Cefalea & \multicolumn{2}{|c|}{29} \\
\hline Exacerbación o empeoramiento de asma & \multicolumn{2}{|c|}{27} \\
\hline IVRS & \multicolumn{2}{|c|}{23} \\
\hline Bronquitis & \multicolumn{2}{|c|}{21} \\
\hline Lumbalgia & \multicolumn{2}{|c|}{18} \\
\hline Artralgia & \multicolumn{2}{|c|}{17} \\
\hline Sinusitis & \multicolumn{2}{|c|}{16} \\
\hline Influenza & \multicolumn{2}{|c|}{13} \\
\hline Reacción en sitio de aplicación & \multicolumn{2}{|c|}{12} \\
\hline Dolor en extremidad & \multicolumn{2}{|c|}{12} \\
\hline Infección del tracto respiratorio & \multicolumn{2}{|c|}{11} \\
\hline Rinitis alérgica & \multicolumn{2}{|c|}{10} \\
\hline Hipertensión & \multicolumn{2}{|c|}{10} \\
\hline
\end{tabular}

5 versus $4 \%$, fatiga 5 versus $4 \%$, influenza 3 versus $2 \%$, infección del tracto urinario 3 versus $2 \%$, dolor en abdomen superior 3 versus $2 \%$, prurito 3 versus $2 \%$, eccema 3 versus $<1 \%$ y espasmos musculares 3 versus $<1 \%{ }^{23,24}$ Entre 6 y $8 \%$ de los sujetos tratados con mepolizumab han desarrollado anticuerpos antimepolizumab. ${ }^{22,23,24} \mathrm{Un} \mathrm{su}$ jeto desarrolló anticuerpos neutralizantes antimepolizumab. Se desconoce la relevancia 
clínica de la presencia de estos anticuerpos, sin embargo, no ha mostrado correlación con el efecto sobre eosinófilos en sangre periférica. En los estudios de extensión no se han observado sujetos con anticuerpos neutralizantes antimepolizumab. Un resumen de los eventos adversos informados en los ensayos clínicos, así como en los estudios de extensión se muestra en el cuadro 2 .

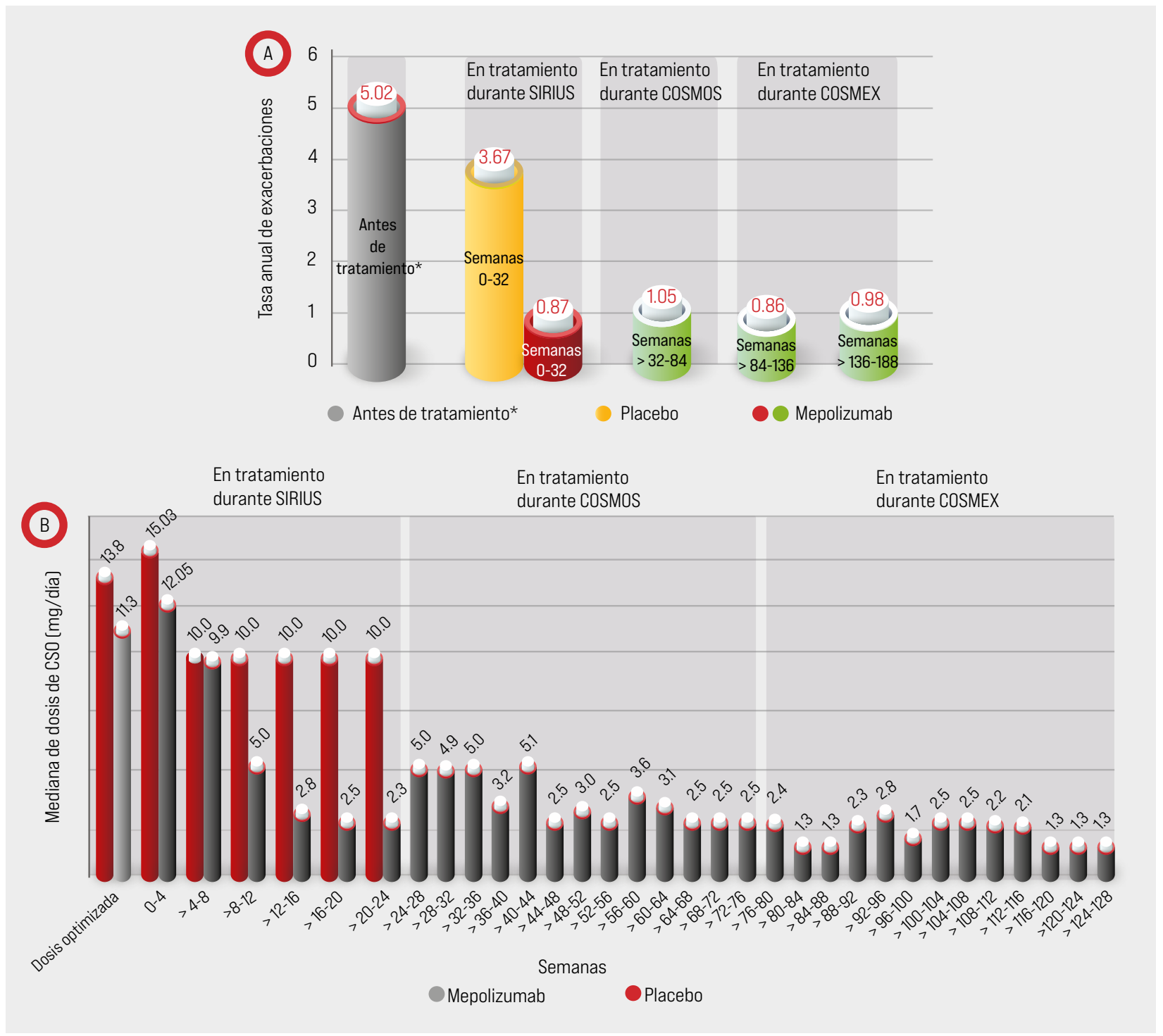

Figura 5. Observaciones de eficacia y efectividad en la población de pacientes con el espectro más grave de asma grave eosinofilica.

A) Barra gris = tasa anual de exacerbaciones en pacientes con el espectro más grave de en el año previo a ingresar al estudio MENSA. Barras amarillas y rojas = tasas anualizadas de exacerbaciones observadas en el grupo placebo (amarilla; $n=24$ ] y en el grupo tratado con mepolizumab (roja; $n=71$ ] en MENSA. Barras verdes = tasas anuales de exacerbaciones observadas en COSMOS y COSMEX, donde todos recibieron tratamiento con 100 mg mepolizumab vía subcutánea cada cuatro semanas. [ $\mathrm{N}=95$ que acumularon $\geq 188$ semanas de observación a lo largo de MENSA, COSMOS y COSMEX].

B] Uso de corticosteroides orales [CEO) a lo largo de SIRIUS, COSMOS, y COSMEX en pacientes que acumularon $\geq 128$ semanas de seguimiento continuo $\left[N=38\right.$, SIRIUS; $n=18$ placebo; $n=20$ mepolizumab]. Las dosis se muestran de acuerdo con prednisona. ${ }^{*}$ Todos los pacientes recibieron tratamiento estándar. 


\section{Comparaciones con otros biológicos}

Actualmente no existen evidencias clínicas derivadas de estudios con comparaciones directas entre los diferentes biológicos para el tratamiento del asma grave. Un análisis comparativo a detalle entre los diferentes biológicos disponibles para el tratamiento de asma grave escapa al objetivo y alcance de este artículo; sin embargo, es importante situar la validez de estas comparaciones en el caso específico de la población de empalme (es decir, pacientes que cumplen criterios de elegibilidad para más de un anticuerpo monoclonal). En este sentido, existen algunas publicaciones que indican la proporción de pacientes con asma grave que son candidatos a tratamiento con alguno de los biológicos mencionados; han informado que entre 55 y $78 \%$ serán candidatos a tratamiento con
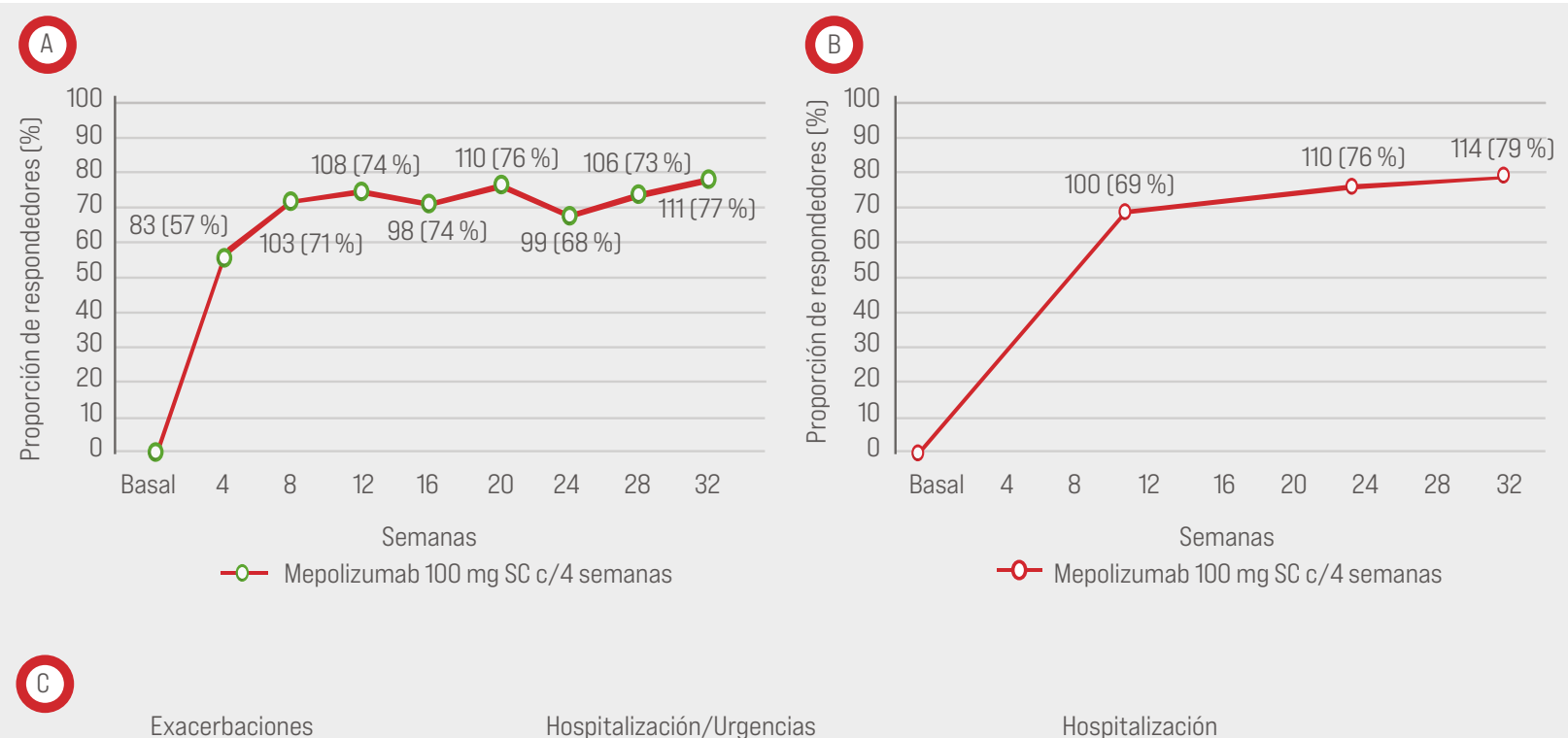

Exacerbaciones

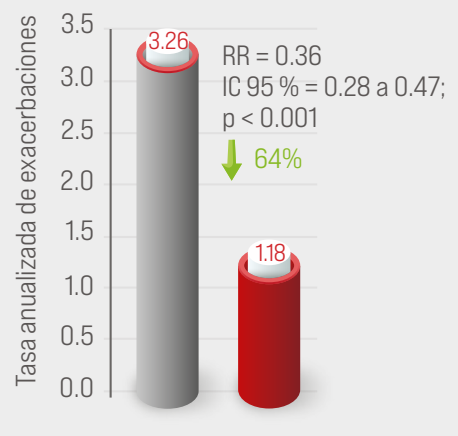

- Posterior a cambio [tramiento con mepolizumab]
Hospitalización/Urgencias

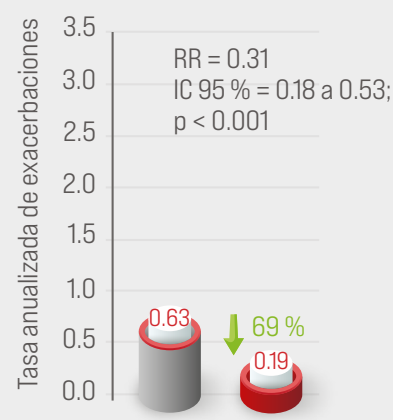

- Previo a cambio [tramiento con omalizumab]

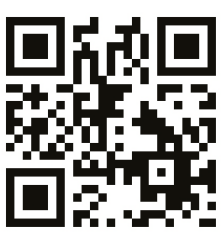

Video

Figura 6. Observaciones de efectividad del estudio OSMO. A] Proporción de respondedores con mejoría clínicamente importante en el control del asma [cambio en Asthma Control Questionnaire $\geq 0.5$ puntos]. B] Proporción de respondedores con mejoría clínicamente importante en calidad de vida [cambio en St. George's Respiratory Questionnaire $\geq 4$ puntos]. C] Magnitud de reducción en exacerbaciones de asma. El código QR lleva a un video ilustrativo del estudio OSMO. *Todas las comparaciones son antes-después tomando en cuenta el estado basal del control de la enfermedad con ACQ 4 semanas previas y al iniciar mepolizumab versus Asthma Control Questionnaire cada 4 semanas, St. George's Respiratory Questionnaire al momento de iniciar mepolizumab versus 12, 24, y 32 semanas, y tasa anual de exacerbaciones de los últimos 12 meses versus tasa anualizada de exacerbaciones a la semana 32 de 0SMO. 
mepolizumab; entre 37 y $66 \%$, a omalizumab; $53 \%$, a benralizumab y $41 \%$, a reslizumab. ${ }^{31,32}$ Estos estudios han señalado que aproximadamente 45 a $53 \%$ de los pacientes con asma grave cumplen criterios para ser tratados con mepolizumab u omalizumab, de forma indistinta. Al considerar los anticuerpos monoclonales anti-IL-5, no todos los pacientes elegibles a tratamiento con mepolizumab lo son para benralizumab. La eficacia clínica demostrada con benralizumab en la población con 150 a 300 eosinófilos/ $\mu \mathrm{L}$ de sangre periférica no demostró diferencia estadísticamente significativa tras ajustar los análisis por multiplicidad (requisito estadístico por la metodología de los estudios). Por esta razón, la población que se espera sea tratable con benralizumab es menor comparada con la población elegible para mepolizumab (es decir, de 68 a $78 \%$ de los pacientes tratables con mepolizumab también podrían ser tratados con benralizumab). ${ }^{31,32}$

Los ensayos clínicos de los diferentes biológicos se han comparado con tratamiento estándar y placebo, lo que ha permitido realizar revisiones sistemáticas y metaanálisis en red (NMA, network meta-analysis) basadas en la comparación de los efectos de cada biológico versus un comparador común (es decir, placebo). La metodología de este tipo de revisiones sistemáticas y metaanálisis ha sido discutida exhaustivamente en otros artículos. Una revisión breve y amigable del tema se encuentra disponible en video escaneando el código QR al margen.

Existen al menos dos revisiones sistemáticas y metaanálisis en red que comparan la eficacia y seguridad de mepolizumab versus omalizumab en pacientes con asma grave eosinofílica alérgica que cumplen criterios de elegibilidad para ambos biológicos. Los desenlaces clínicos estudiados han incluido las tasas de exacerbaciones, control de la enfermedad y mejoría en la función pulmonar. Estos estudios han documentado similitud en los perfiles de eficacia y seguridad de ambos biológicos. ${ }^{33,34}$ Igualmente se han publicado diferentes ITC en los que se comparan los diferentes anti-IL5, 35,3637,38,39,40,41,42 así como comparaciones entre los diferentes biológicos disponibles para el tratamiento de pacientes con asma grave (mepolizumab, omalizumab, benralizumab, reslizumab, dupilumab). ${ }^{43,44,45,46,47}$ También es importante mencionar que actualmente hay al menos un ensayo clínico de asignación aleatoria con comparaciones directas y paralelas entre mepolizumab y omalizumab registrado y en curso (NCT03476109). Se esperan más estudios que respondan estas interrogantes con mayor precisión.

\section{Evidencias de vida real}

Todos los clínicos que evalúan y tratan a pacientes con asma grave reconocen que las evidencias generadas y publicadas en ensayos clínicos son valiosas e informativas respecto a la eficacia y seguridad de los diferentes medicamentos que actualiza su arsenal terapéutico. Sin embargo, la realidad en el consultorio frecuentemente reta estas evidencias por factores que comúnmente no están apropiadamente representados en los ensayos clínicos (por ejemplo, múltiples comorbilidades, polifarmacia, tabaquismo activo, no cumplimiento de los criterios espirométricos, etcétera). Diversas intervenciones estudiadas en condiciones controladas (es decir, ensayos clínicos de asignación aleatoria) han informado evidencias de eficacia y seguridad que en la práctica rutinaria se ven atenuadas o modificadas.

Lo anterior constituye la brecha entre eficacia y efectividad, influida por las diferencias en homogeneidad versus heterogeneidad de las poblaciones intervenidas y las relaciones riesgo/beneficio de acuerdo con las condiciones clínicas donde son utilizadas (cumplir criterios estrictos de inclusión versus cumplir con la indicación terapéutica aprobada). ${ }^{48}$ Por estas razones, la disponibilidad de evidencias generadas en la práctica clínica rutinaria (es decir, evidencias de vida real) es de especial interés. 
Mepolizumab cuenta con diferentes evidencias de vida real alrededor del mundo, con información suficiente de los pacientes tratados en la práctica clínica rutinaria. Un resumen de estas evidencias se proporciona en el cuadro $3 .{ }^{23,24,25,30,49-71}$

De acuerdo con el cuadro 3, las observaciones de los pacientes tratados con mepolizumab en la práctica clínica rutinaria (evidencias de vida real) son consistentes con los resultados de eficacia generados en condiciones controladas. Estas evidencias respaldan los beneficios clínicos del tratamiento de pacientes con asma grave eosinofílica con mepolizumab y son generalizables a la práctica clínica rutinaria.

\section{Aspectos prácticos para el consultorio}

Mepolizumab se comercializa por GlaxoSmithKline con el nombre de Nucala. En México se cuenta con la presentación de vial liofilizado, que se reconstituye mecánicamente con

\begin{tabular}{|c|c|c|}
\hline & Evidencias de vida real & $\begin{array}{l}\text { Evidencias de ensayos } \\
\text { clínicos aleatorizados }\end{array}$ \\
\hline \multicolumn{3}{|l|}{ Características basales de los pacientes } \\
\hline Rango de exacerbaciones clínicamente relevantes & 2.3-5.8 & 2.7-3.8 \\
\hline Promedio de eosinófilos en biometría hemática[células/ $\mu \mathrm{L}]$ & $330-1.450$ & $230-450$ \\
\hline Proporción de pacientes corticodependientes & $28-93 \%$ & $23-27 \%$ \\
\hline \multicolumn{3}{|l|}{ Proporción de pacientes con comorbilidad } \\
\hline Rinitis alérgica & $67-70 \%$ & $41-52 \%$ \\
\hline Pólipos nasales & $19-85 \%$ & $14-26 \%$ \\
\hline \multicolumn{3}{|l|}{ Desenlaces clínicos observados con tratamiento estándar + mepolizumab } \\
\hline Reducción en tasa anual/anualizada de exacerbaciones clínicamente relevantes & $34-86 \%$ & 53 a $58 \%$ \\
\hline $\begin{array}{l}\text { Reducción en tasa anual/anualizada de exacerbaciones que requieren visita a } \\
\text { urgencias u hospitalización }\end{array}$ & $35-83 \%$ & $61-68 \%$ \\
\hline Reducción en dosis de corticosteroide oral sistémico & 50 a $100 \%$ & $50-100 \%$ \\
\hline $\begin{array}{l}\text { Proporción de pacientes corticodependientes que logran disminuir } \geq 50 \% \\
\text { dosis de corticosteroide oral sistémico }\end{array}$ & $23-77 \%$ & $54 \%$ \\
\hline $\begin{array}{l}\text { Proporción de pacientes corticodependientes que logran suspender corticoste- } \\
\text { roide oral sistémico }\end{array}$ & $30-100 \%$ & $14-58 \%$ \\
\hline Reducción de eosinófilos en sangre periférica & $69-92 \%$ & $78-86 \%$ \\
\hline Mejoría en control del asma [Asthma Control Questionnaire; puntos] & $0.8-2.0$ & $0.4-0.52$ \\
\hline $\begin{array}{l}\text { Mejoría en control del asma [Asthma Control Test; puntos o porcentaje de } \\
\text { sujetos en los que se log diferencia mínima clínicamente importante] }\end{array}$ & $1.7-10$ & $50-100 \%$ \\
\hline Proporción de pacientes que descontinuaron por falta de eficacia & $3.5-20 \%$ & $0-3 \%$ \\
\hline Proporción de pacientes que descontinuaron por evento adverso & $<1-10 \%$ & $<1-5 \%$ \\
\hline
\end{tabular}


$1.2 \mathrm{~mL}$ de agua estéril inyectable, para administrar $1 \mathrm{~mL}$ que contiene $100 \mathrm{mg}$ por dosis, y se aplica por vía subcutánea cada cuatro semanas. Para su almacenamiento se requiere mantener el medicamento por debajo de $25{ }^{\circ} \mathrm{C}$ en su empaque original, en un lugar limpio y seco. La indicación aprobada en México para mepolizumab es consistente con la de otros países y permite la correcta identificación del perfil de pacientes en los que se predice respuesta clínica favorable (es decir, adolescentes y adultos $\geq 12$ años de edad con asma grave eosinofílica, tratados con dosis altas de corticosteroides más un segundo controlador, que en el último año han tenido dos o más exacerbaciones clínicamente relevantes y en quienes se documenta $\geq 150$ eosinófilos $/ \mu \mathrm{L}$ en sangre periférica al momento de la evaluación $o \geq 300$ eosinófilos/ $\mu \mathrm{L}$ en sangre periférica en los últimos 12 meses).

\section{Conclusiones}

Es indispensable que el especialista que evalúa, diagnostica y trata pacientes con asma grave se mantenga actualizado en las diferentes opciones terapéuticas disponibles. Identificar oportunamente al paciente con asma grave y tener claridad acerca del mecanismo fisiopatogénico responsable de esa gravedad, lo habilita para proporcionar un tratamiento específico con mayores probabilidades de éxito. La mayoría de los pacientes con asma grave cursan con evidencia de inflamación eosinofílica. Mepolizumab es un anticuerpo monoclonal que inhibe específicamente la señalización de IL-5 y con ello disminuye la inflamación eosinofílica. Agregado al tratamiento estándar de pacientes con asma grave eosinofílica, mepolizumab disminuye significativamente las exacerbaciones de asma, mejora el control de la enfermedad, permite la reducción de dosis o retiro de corticosteroides orales en pacientes corticodependientes y mejora significativamente la calidad de vida relacionada con la salud. Estas evidencias de eficacia y seguridad han sido generadas bajo los más altos estándares de ensayos clínicos en condiciones clínicas controladas. Más relevante para la práctica clínica profesional es que estas evidencias han sido confirmadas en estudios de vida real, lo que sustenta la consistencia y durabilidad en escenarios similares a la práctica que se ejerce en los consultorios o en las instituciones de salud.

\section{Declaraciones}

Financiamiento

El apoyo editorial (incluido el diseño de figuras, por Perla Daniella Ambrocio González, de IT4U Diseño y Desarrollo) fue patrocinado por GlaxoSmithKline México, S. A de C. V.

Conflictos de interés

Armando Partida-Gaytán, Marco Polo Macías, Alejandro Raimondi y Emilio Pizzichini son empleados actuales y tienen acciones de GlaxoSmithKline. Luis Torre-Bouscoulet no tiene conflictos de interés que declarar.

\section{Referencias}

1. Chung KF, Wenzel SE, Brozek JL, Bush A, Castro M, Sterk PJ, et al. International ERS/ATS guidelines on definition, evaluation and treatment of severe asthma. Eur Respir J. 2014;43[2]:343-373. D0I: 10.1183/09031936.00202013 
Partida-Gaytán A et al. Mepolizumab para asma grave eosinofílica

2. Proceedings of the ATS workshop on refractory asthma: current understanding, recommendations, and unanswered questions. American Thoracic Society. Am J Respir Crit Care Med. 2000;162[6]:2341-2351. D0I: 10.1164/ajrccm.162.6.ats9-00

3. Busse WW. Definition and Impact. En: Chung KF, Israel E, Gibson PG, editores. Severe asthma. Reino Unido: European Respiratory Society; 2019.

4. McDonald VM, Kennington E, Hyland ME. Understanding the experience of people living with severe asthma. En: Chung KF, Israel E, Gibson PG, editores. Severe asthma. Reino Unido: European Respiratory Society; 2019.

5. Lane S, Molina J, Plusa T. An international observational prospective study to determine the cost of asthma exacerbations [COAX]. Respir Med. 2006;100[3]:434-450. D0l: 10.1016/j.rmed.2005.06.012

6. Asher MI, Montefort S, Björkstén B, Lai CKW, Strachan DP, Weikand Sk, et al. Worldwide time trends in the prevalence of symptoms of asthma, allergic rhinoconjunctivitis, and eczema in childhood: ISAAC Phases One and Three repeat multicountry cross-sectional surveys. Lancet. 2006;368[9537]:733-743. D0l: 10.1016/S0140-6736[06]69283-0

7. Menezes AM, Hallal P, Montes-de Oca M, Muino A, López-Varela, Talamo C, et al. Prevalence of asthma in Latin American middle-aged and older adults and its overlap with diagnosis of COPD. Eur Respir J. 2011;38[Suppl 55):4136.

8. The Global Asthma Report 2018. Nueva Zelanda: Global Asthma Network; 2018. Disponible en: http:// globalasthmareport.org/Global\%20Asthma\%20Report\%202018.pdf

9. Población [Internet]. México: Instituto Nacional de Estadística y Geografía; 2020. Disponible en: https:// www.inegi.org.mx/temas/estructura/default.html\#Informacion_general

10. Holguín F, Cardet JC, Chung KF, Diver S, Ferreira DS, Gaga M, et al. Management of severe asthma: a European Respiratory Society/American Thoracic Society guideline. Eur Respir J. 2020;55(1):1900588. D0I: 10.1183/13993003.00588-2019

11. Hekking PPW, Wener RR, Amelink M, Zwinderman AH, Bouvy ML, Bel EH. The prevalence of severe refractory asthma. J Allergy Clin Immunol. 2015;135[4]:896-902. D0I: 10.1016/j.jaci.2014.08.042

12. Global Strategy for Asthma Management and Prevention [Internet]. EE. UU.: Global Initiative for Asthma; 2020. Disponible en:https://ginasthma.org/wp-content/uploads/2020/06/GINA-2020-report_20_06_041-wms.pdf

13. British guideline on the management of asthma [Internet]. Escocia: Health Improvement Scotland; 2019. Disponible en: https://www.sign.ac.uk/sign-158-british-guideline-on-the-management-of-asthma

14. GEMA 4.4. Guía española para el manejo del asma. GEMA44 Guía española para el manejo del asma. España: Luzán 5; 2019. Disponible en: https://semg.es/images/documentos/GEMA_4_4.pdf

15. Expert panel report 3: guidelines for the diagnosis and management of asthma. EE. UU.: National Heart, Lung, and Blood Institute/National Asthma Education and Prevention Program; 2007. Disponible en: https://www.nhlbi.nih.gov/sites/default/files/media/docs/EPR-3_Asthma_Full_Report_2007.pdf

16. Larenas-Linnemann D, Salas-Hernández J, Vázquez-García JC, Ortiz-Aldana I, Fernández-Vega M, del RíoNavarro BE, et al. Guía Mexicana del Asma: GUIMA 2017. Rev Alerg Mex. 2017;64[Supl 1]:S11-S128. Disponible en: https://revistaalergia.mx/ojs/index.php/ram/article/download/272/406/2129

17. Busse WW. Biological treatments for severe asthma: a major advance in asthma care. Allergol Int. 2019;68[2]:158-166. D0I: 10.1016/j.alit.2019.01.004

18. Greenfeder S, Umland SP, Cuss FM, Chapman RW, Egan RW. Th2 cytokines and asthma. The role of interleukin-5 in allergic eosinophilic disease. Respir Res. 2001;2[2]:71-79. DOI: 10.1186/rr41

19. Indicación para prescribir amplia - Nucala [Internet]. Canadá: GSKpro; 2016.

20. Haldar P, Pavord ID, Shaw DE, Berry MA, Thomas M, Brightling CE, et al. Cluster analysis and clinical asthma phenotypes. Am J Respir Crit Care Med. 2008;178[3]:218-224. DOl: 10.1164/rccm.200711-17540C

21. de Carvalho-Pinto RM, Cukier A, Angelini L, Antonangelo L, Maud T, Rabe KF, et al. Clinical characteristics and possible phenotypes of an adult severe asthma population. Respir Med. 2012;106(1):47-56. D0l: 10.1016/j. rmed.2011.08.013

22. Pavord ID, Korn S, Howarth P, Bleecker ER, Buhl R, Keene ON, et al. Mepolizumab for severe eosinophilic asthma [DREAM]: a multicentre, double-blind, placebo-controlled trial. Lancet. 2012;380[9842]:651-659. DOI: 10.1016/S0140-6736[12]60988-X 
23. Ortega HG, Liu MC, Pavord ID, Brusselle GG, FitxGerald JM, Chetta A, et al. Mepolizumab treatment in patients with severe eosinophilic asthma. N Engl J Med. 2014;371(13):1198-1207. DOI: 10.1056/NEJMoa1403290

24. Bel EH, Wenzel SE, Thompson PJ, Prazma CM, Keene ON, Yancey SW, et al. Oral glucocorticoid-sparing effect of mepolizumab in eosinophilic asthma. N Engl J Med. 2014;371(13):1189-1197. DOI: 10.1056/NEJMoa1403291

25. Chupp GL, Bradford ES, Albers FC, et al. Efficacy of mepolizumab add-on therapy on health-related quality of life and markers of asthma control in severe eosinophilic asthma [MUSCA]: a randomised, double-blind, placebo-controlled, parallel-group, multicentre, phase 3b trial. Lancet Respir Med. 2017;5[5]:390-400. D0l: 10.1016/S2213-2600[17)30125-X

26. Ortega HG, Yancey SW, Mayer B, Gunsoy NB, Keene ON, Bleecker ER, et al. Severe eosinophilic asthma treated with mepolizumab stratified by baseline eosinophil thresholds: a secondary analysis of the DREAM and MENSA studies. Lancet Respir Med. 2016;4[7]:549-556. DOl: 10.1016/S2213-2600(16)30031-5

27. Humbert M, Albers FC, Bratton DJ, Yancey SW, Liu MC, Hozawa S, et al. Effect of mepolizumab in severe eosinophilic asthma according to omalizumab eligibility. Respir Med. 2019;154:69-75. DOI: 10.1016/j. rmed.2019.06.004

28. Khatri S, Moore W, Gibson PG, Leigh R, Bourdin A, Maspero J, et al. Assessment of the long-term safety of mepolizumab and durability of clinical response in patients with severe eosinophilic asthma. J Allergy Clin Immunol. 2019;143[5]:1742-1751.e7. D0l: 10.1016/j.jaci.2018.09.033

29. Lugogo N, Domingo C, Chanez P, et al. Long-term efficacy and safety of mepolizumab in patients with severe eosinophilic asthma: a multi-center, open-label, phase Illb study. Clin Ther. 2016;38[9]:2058-2070. e1. DOI: 10.1016/j.clinthera.2016.07.010

30. Khurana S BG, Bel EH, FitzGerald JM, Masoli M, et.al. Long-term safety and clinical benefit of mepolizumab in patients with the most severe eosinophilic asthma: the COSMEX study. Clin Ther. 2019;41[10]:2041-2056. e5. DOl: 10.1016/j.clinthera.2019.07.007

31. Jeimy S, Tsoulis MW, Hachey J, Kim H. Eligibility of monoclonal antibody-based therapy for patients with severe asthma: a Canadian cross-sectional perspective. Allergy Asthma Clin Immunol. 2018;14[68]:68. D0I: 10.1186/s13223-018-0301-6

32. Menzella F, Galeone C, Ruggiero P, Bagnasco D, Catellani C, Facciolongo N. Biologics and bronchial Thermoplasty for severe refractory asthma treatment: from eligibility criteria to real practice. A crosssectional study. Pulm Pharmacol Ther. 2020;60(101874):101874. DOI: 10.1016/j.pupt.2019.101874

33. Cockle SM, Stynes G, Gunsoy NB, Parks D, Alfonso-Cristancho R, Wex J, et al. Comparative effectiveness of mepolizumab and omalizumab in severe asthma: an indirect treatment comparison. Respir Med. 2017;123:140-148. DOI: 10.1016/j.rmed.2016.12.009

34. Nachef Z, Krishnan A, Mashtare T, Zhuang T, Jeffery M. Omalizumab versus mepolizumab as add-on therapy in asthma patients not well controlled on at least an inhaled corticosteroid: a network metaanalysis. J Asthma. 2018;55[1]:89-100. DOl: 10.1080/02770903.2017.1306548

35. Wang FP, Liu T, Lan Z, Li SY, Mao H. Efficacy and safety of anti-interleukin- 5 therapy in patients with asthma: a systematic review and meta-analysis. PLoS One. 2016;11(11]:e0166833. DOl: 10.1371/journal.pone.0166833

36. Farne HA WA, Powell C, Bax L, Milan SJ. Anti-IL5 therapies for asthma. Cochrane Database Syst Rev. 2017[9]:1-102. D0l: 10.1002/14651858.CD010834.pub3

37. He LL, Zhang L, Jiang L, Xu F, Fei DS. Efficacy and safety of anti-interleukin-5 therapy in patients with asthma: a pairwise and Bayesian network meta-analysis. Int Immunopharmacol. 2018;64:223-31. DOI: 10.1016/j.intimp.2018.08.031

38. Bourdin A, Husereau D, Molinari N, Golam S, Linder L, Xu X, et al. Matching-adjusted indirect comparison of benralizumab versus interleukin- 5 inhibitors for the treatment of severe asthma: a systematic review. Eur Respir J. 2018;52[5]:1801393. DOI: 10.1183/13993003.01393-2018

39. Henriksen DP, Bodtger U, Sidenius K, et al. Efficacy, adverse events, and inter-drug comparison of mepolizumab and reslizumab anti-IL-5 treatments of severe asthma-a systematic review and metaanalysis. Eur Clin Respir J. 2018;5[1]:1536097. D0l: 10.1080/20018525.2018.1536097.

40. Yan K, Balijepalli C, Sharma R, Barakat S, Sun SX, Falcao S, et al. Reslizumab and mepolizumab for moderate-to-severe poorly controlled asthma: an indirect comparison meta-analysis. Immunotherapy. 2019;11(17):1491-1505. DOI: 10.2217/imt-2019-0113 
Partida-Gaytán A et al. Mepolizumab para asma grave eosinofílica

41. Casale TB, Pacou M, Mesana L, et al. Reslizumab compared with benralizumab in patients with eosinophilic asthma: a systematic literature review and network meta-analysis. J Allergy Clin Immunol Pract. 2019;7[1]:122-130.e1. D0I: 10.1016/j.jaip.2018.08.036

42. Busse W, Chupp G, Nagase H, Albers FC, Doyle S, Shen Q, et al. Anti-IL-5 treatments in patients with severe asthma by blood eosinophil thresholds: indirect treatment comparison. J Allergy Clin Immunol. 2019;143[1]:190-200.e20. DOI: 10.1016/j.jaci.2018.08.031

43. Iftikhar IH, Schimmel M, Bender W, Swenson C, Amrol D. Comparative efficacy of anti IL-4, IL-5 and IL-13 drugs for treatment of eosinophilic asthma: a network meta-analysis. Lung. 2018;196[5]:517-530. D0l: 10.1007/s00408-018-0151-5

44. Edris A, de Feyter S, Maes T, Joos G, Lahousse L. Monoclonal antibodies in type 2 asthma: a systematic review and network meta-analysis. Respir Res. 2019;20[1]:179. D0I: 10.1186/s12931-019-1138-3

45. Calzetta L MM, Rogliani P. Monoclonal antibodies in severe asthma: is it worth it? Expert Opinion Drug Metab Toxicol. 2019;15[6]:517-520. DOl: 10.1080/17425255.2019.1621837

46. Agache I, Beltran J, Akdis C, Akdis M, Canelo-Aybar C, Casale T, et al. Efficacy and safety of treatment with biologicals [benralizumab, dupilumab, mepolizumab, omalizumab and reslizumab] for severe eosinophilic asthma. A systematic review for the EAACI Guidelines - recommendations on the use of biologicals in severe asthma. Allergy. 2020;75[5]:1023-1042. D0l: 10.1111/all.14221

47. Ramonell RP, Iftikhar IH. Effect of anti-IL5, anti-IL5R, anti-IL13 therapy on asthma exacerbations: a network meta-analysis. Lung. 2020;198(1):95-103. DOl: 10.1007/s00408-019-00310-8

48. Eichler HG, Abadie E, Breckenridge A, Flamion B, Leufkens H, et al. Bridging the efficacy-effectiveness gap: a regulator's perspective on addressing variability of drug response. Nat Rev Drug Discov. 2011;10[7]:495506. DOl: $10.1038 /$ nrd3501

49. Hernández-Martin I, Barranco P, Sanchez-Jareño M, Palao-Ocharan P, Domínguez-Ortega J, Luna-Porta JA, et al. Patients with severe eosinophilic asthma treated with mepolizumab: results from our clinical practice. J Allergy Clin Immunol. 2019;143(2). DOl: 10.1016/j.jaci.2018.12.287

50. Feijoo-Paz, . Clinical utility of mepolizumab in real-life practice in severe asthma unit of Madrid [Spain]. Allergy. 2018;73[Suppl 105]:671.

51. Kurosawa M, Sutoh E. Prospective open-label study of 48-week subcutaneous administration of mepolizumab in Japanese patients with severe eosinophilic asthma. J Investig Allergol Clin Immunol. 2019;29(1):40-45. DOl: 10.18176/jiaci.0285. PubMed PMID: 29957591

52. Bjerrum AS, Schmid J, Skjold T. Oral glucocorticoid-sparing effects of mepolizumab. A real-life study. Eur Respir J. 2018;52:601. D0I: 10.1183/13993003.congress-2018.PA601

53. Bjerrum AS, Skjold T, Schmidt J. Baseline characteristics of 36 mepolizumab-patients. Experiences from the clinical practice. Eur Respir J. 2017;50:PA3588. DOI: 10.1183/1393003.congress-2017.PA3588

54. Farah CS, Badal T, Reed N, Rogers PG, King GG, Thamrin C, et al. Mepolizumab improves small airway function in severe eosinophilic asthma. Respir Med. 2019;148:49-53. D0l: 10.1016/j.rmed.2019.01.016

55. Seccombe L, Rogers P, Reed N, Badal T, Thamrin C, King G, et al. Mepolizumab improves small airway function in severe eosinophilic asthma. Eur Respir J. 2018;52:PA2434. DOI: 10.1183/13993003.congress-2018.PA2434

56. d'Ancona G, Liu B, Wei L, Green L, Fernandes M, Roxas C, et al. S81 does adherence to inhaled therapy change following initiation of mepolizumab in the treatment of severe asthma? Thorax. 2018;73[Suppl 4):A50-A51. DOI: 10.1136/thorax-2018-212555.87

57. Llanos JP, Bell CF, Packnett E, Thiel E, Irwin DE, Hahn B, et al. Real-world characteristics and disease burden of patients with asthma prior to treatment initiation with mepolizumab or omalizumab: a retrospective cohort database study. J Asthma Allergy. 2019;12:43-58. DOI: 10.2147/JAA.S189676

58. Ortega H, Hahn B, Tran JN, Bell C, Shams SA, Llanos JP. Disease burden in patients with asthma before initiating biologics: a retrospective cohort database study. Allergy Asthma Proc. 2019;40[3]:146-153. DOI: 10.2500/aap.2019.40.4220

59. LaHood NA, Robinson LB, Long AA. Clinical indication and outcomes of mepolizumab therapy at an academic medical center. J Allergy Clin Immunol. 2019;143[2]:AB96. D0I:10.1016/j.jaci.2018.12.293

60. Weir E, Paton J. Mepolizumab in adolescents with severe eosinophilic asthma not eligible for omalizumab: one center's early clinical experience. J Asthma. 2020;57[5]:521-524. D01: 10.1080/02770903.2019.1579833 
61. Zhang P, Vitari CA, Wenzel SE. Real world effectiveness and safety of anti-IL-5/mepolizumab in an academic severe asthma clinic. Am J Respir Crit Care Med. 2020;201:A3187.

62. Kavanagh J, Green L, Fernandes M, Bolton M, d'Ancona G, Roxas C, et al. Assessment of early responder characteristics to mepolizumab in steroid-dependent eosinophilic asthma. Am J Respir Crit Care Med. 2020;197:A1363.

63. Harrison T, Canonica G, Gemzoe K, Maxwell A, Yang S, Joksaite S, et al. Effectiveness and safety of mepolizumab in real-world clinical practice: the REALITI-A study. Pneumologie. 2020;74. DOl: 10.1055/s0039-3403114

64. Strauss RA, Jawhari N. Mepolizumab in the treatment of severe eosinophilic asthma: results from a physician in the field. Ann Allergy Asthma Immunol. 2018;121(1):121-123. D0I: 10.1016/j.anai.2018.04.016

65. Benjamin MR, Bochner BS, Peters AT. Mepolizumab use: post-approval academic practice experience. Ann Allegy Asthma Immunol. 2018;121(1):126-128. DOI: 10.1016/j.anai.2018.04.001

66. Gruber A, Taillé C, Chanez P, Devouassoux G, Didier A, Pison C, et al. Real-life experience with mepolizumab in the French early access program for severe eosinophilic asthma. Eur Respir J. 2019;54:PA1654. DOI: 10.1183/13993003.congress-2019.PA1654

67. Pelaia C, Busceti MT, Solinas S, et al. Real-life evaluation of the clinical, functional, and hematological effects of mepolizumab in patients with severe eosinophilic asthma: results of a single-centre observational study. Pulm Pharmacol Ther. 2018;53:1-5. DOl: 10.1016/j.pupt.2018.09.006

68. Venkata-Subramani M, Saygin D, McCarroll S, Micklewright S, Ibrahim L, Taliercio RM, et al. Mepolizumab treatment in severe asthma: a case series. Am J Respir Crit Care Med. 2020;201:A5334.

69. Hahn B, Llanos-Ackert JP, Ortega H, Packnett E, Irwin D, Riehle E, et al. Disease severity and baseline characteristics of patients receiving mepolizumab or omalizumab in employer claims database: a realworld experience. 2018;141(2):AB10. DOI: 10.1016/j.jaci.2017.12.033

70. Bagnasco D, Milanese M, Rolla G, Lombardi C, Bucca C, Heffler E, et al. The North-Western Italian experience with anti IL-5 therapy and comparison with regulatory trials. World Allergy Organ J. 2018;11[1]:34. DOI: 10.1186/s40413-018-0210-7

71. Antonicelli L, Gobbi A, Bilò MB, Garritani MS, Brianzoni MF, Dellacà. Change of lung function in severe eosinophilic asthma undergoing treatment with anti-interleukin-5 monoclonal antibody. Eur Respir J. 2018;52:PA1133. DOI: 10.1183/13993003.congress-2018.PA1133 